\title{
OUTRO LADO DA JUVENTUDE: ACOMPANHAMENTO TERAPÊUTICO NA TRAVESSIA DO ENVELHECER
}

\section{ARTIGO ORIGINAL}

BERLIKOWSKI, Loreni Teresinha ${ }^{1}$

BERLIKOWSKI, Loreni Teresinha. Outro lado d05a juventude: Acompanhamento terapêutico na travessia do envelhecer. Revista Científica Multidisciplinar Núcleo do Conhecimento. Ano 05, Ed. 10, Vol. 22, pp. 145-161. Outubro de 2020. ISSN: 24480959, Link de acesso: https://www.nucleodoconhecimento.com.br/psicologia/acompanhamentoterapeutico

\section{RESUMO}

O objetivo desse trabalho é traçar caminho com materiais já publicado em artigos e livros, anais de eventos científicos, sem uma delimitação específica de temporalidade, possibilitando a reflexão dos mais variados aspectos relativos à temática da pesquisa, para compreender o fazer do Acompanhamento Terapêutico, suas mudanças através de sua história. Neste contexto específico conhecer a vivência e a prática de uma psicóloga que atua com o dispositivo acompanhamento terapêutica com o público idoso, tendo como objetivo advogar pela inclusão da pessoa idosa no contexto social e familiar. Contribuindo e ressignificando a novas trajetórias considerando a subjetividade individual de cada indivíduo, potencializando a novos vínculos que deseje construir como um ser social de direitos. O objetivo do AT é ser um agente de ressocialização para possibilitar direcionar a novos espaços que a pessoa idosa deseje estar.

Palavras-chave: Acompanhamento terapêutico, envelhecer, inclusão.

\footnotetext{
${ }^{1}$ Bacharel em Psicologia; Pós em Neuropsicologia.
} 


\section{INTRODUÇÃO}

Acompanhamento Terapêutico (AT), com sua visão clínica vai além do consultório tradicional, pensa e advoga em favor das diferenças, reverberando nas políticas que envolvem o sujeito no contexto social. O objetivo geral é analisar as contribuições e estratégia do acompanhamento terapêutico como ferramenta de uma psicóloga.

O Brasil apresenta um crescimento significativo na população de pessoas idosas, pensando nesse indivíduo buscou-se conhecer a vivência, e prática de uma psicóloga que atua com o dispositivo do acompanhamento terapêutico para o público idoso. Ou seja, a psicóloga AT que desbrava esse novo território, no caso, envelhecimento na contemporaneidade esforçando-se em construir redes de suporte para superar certos impasses clínicos.

Enquanto hipótese, acredita-se que a inserção de um acompanhamento terapêutico na área da psicologia tem muito a contribuir, por trabalhar centrado na promoção a saúde, também conta com estratégias de prevenção que possibilitará a esse grupo ser retirando do declínio de incapacidade e limitações, para um convívio social devolvendo-Ihe a palavra e a capacidade de pensar, de desejar ser pertencente ao contexto social, que são negados ao envelhecer.

Para responder o questionamento proposto no estudo, sobre acompanhamento terapêutico, buscou-se esclarecer como a psicóloga utiliza essa ferramenta é faz consolidar-se de forma relevante na clínica realizando atendimentos com o público idoso. Respeitando a subjetividade, sem ameaçar a autonomia ou necessidade da pessoa idosa, já que o fenômeno do envelhecer causa mudanças de caráter físico e psicológico, com grandes perdas, luto, solidão é desamparo.

\section{ENVELHECER NA CONTEMPORANEIDADE}

Pensar em envelhecimento e suas diversas dimensões, sendo, culturais, políticas, econômicas, é uma forma de construir história sobre o contexto que envolve o indivíduo, seja no capitalismo na produtividade, a pessoa idosa, por esgotar a sua 
capacidade de produção, passa a um não lugar, sua diferença produtiva no mercado capitalista o impulsiona para a exclusão social (BARBIERI, 2013).

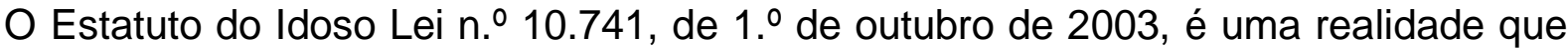
considera que pessoa idosa é aquela com idade igual ou superior a 60 anos. O (IBGE), aponta para uma população brasileira que está em trajetória de envelhecimento e, até 2060, o percentual de pessoas com mais de 65 anos passará dos atuais 9,2\% para $25,5 \%$. para cada 4 brasileiros um será idoso. Esta projeção divulgada e dirigida pelo Instituto Brasileiro de Geografia e Estatística (IBGE) 2018.

Negreiro (2007), chama a atenção para o aumento da expectativa de vida do indivíduo, considerando ser uma grande conquista da sociedade moderna, mas também devese levar em consideração que o fato de viver mais não significa necessariamente ter qualidade de vida.

Barbieri (2013), pontua a importância de dar visibilidade às questões relativas ao envelhecimento humano, uma forma de fortalecer a luta de inclusão para a pessoa idosa e sua plena constituição como sujeito pertencente ao meio social. Ter o olhar humanizado sobre a subjetividade da pessoa idosa é o foco do profissional AT, que trabalha para resgatar o espaço no contexto social do indivíduo.

Peixeiro (2005) declara, o AT oferece seu trabalho clínico, mas com o olhar político, por estar sempre voltado para a inclusão do indivíduo, possibilitando a construção de pontes de amparo privilegiando a pessoa idosa na fase que é delicada para ela, seu trabalha tem essa visão por ser uma clínica que atuou por muitos anos junto a instituições psiquiátricas voltada para pacientes psicóticos, seus primeiros ATs eram jovens estagiários, denominados, amigos qualificados na época, hoje reconhecidos como (ATs), profissionais de acompanhamento terapêutico. Seu trabalho está em criar possibilidades de laços com menos danos.

Os maus tratos, descasos e negligência é cada vez menos comum no campo da saúde mental, efeito de anos de luta, movimento antimanicomiais no Brasil. No contexto do campo da velhice, ainda é testemunhado maneiras desumanas de acolhimento. $O$ 
sujeito que envelhece acaba se deparando com um cenário pobre de alternativas para o futuro, situação em que a construção de sentidos para a vida é tarefa quase impossível, sobrando como única alternativa a morte (BARBIERE, 2013).

\section{HISTÓRIA DO ACOMPANHAMENTO TERAPÊUTICO}

O surgimento do Acompanhamento Terapêutico, foi no campo da saúde mental, na Argentina, em meados de 1970, como resposta à excessiva e desumana psiquiatrização, que ocorreu a partir do século XIX (PEIXEIRO, 2005).

Gonçalves (2001), fala sobre essa visão da loucura, na idade Média, tinha-se uma visão muito trágica sobre a loucura, passando a ocupar um lugar sinistro, onde o diferente não era aceito pela sociedade nem pelos familiares como (deficiência intelectual, sujeitos improdutivos), eram pessoas marginalizadas havendo um distanciamento entre os reconhecidos como sujeitos normais e produtivos.

No Brasil em 1901 foi fundado o Hospício de Juquery pelo doutor Franco da Rocha, foi um exemplo de alienismo nesse período foi oferecido seu trabalho como terapêutico, para indivíduos que se encontravam em asilos, faziam uso de métodos como a traumoterapia, pancadas aferidas, malarioterapia - inoculação da malária nos pacientes para que, por meio de febre, o sujeito viesse a recuperar-se, tratamento terapêutica para doença mental considerada condições desumanas nos asilos psiquiátricos. Foi preciso algumas décadas para que a eficácia terapêutica fosse colocada em questão (BERGER; MORETTIN; NETO, 1991).

A loucura passou a ser olhada por outro anglo, começou a ser pensado em criar locais de acolhimento, reconhecido como refúgio, onde o poder da demanda contida no discurso do sujeito louco pudesse ser reconhecido. Surgiu espaço clínico de tratamento das primeiras comunidades terapêuticas, onde os pacientes circulavam livremente e exerciam diversas atividades uma forma de reabilitação pessoal e social. surgiu no, Rio de Janeiro, São Paulo e Porto Alegre, sendo elas as primeiras a ofertar o trabalho nas instituições terapêuticas (PEIXEIRO, 2005). 
Peixeiro (2005) declara que o propósito da equipe era criar um ambiente terapêutico, envolvendo pacientes no contexto familiar visitando suas casas, conhecendo seus amigos. Os amigos qualificados eram fundamental e trabalhavam com uma abordagem clínica de amparo destinada aos pacientes com os quais as abordagens terapêuticas clássicas fracassavam.

A prática desses profissionais é reconhecida por terem uma boa aptidão de ação, há mais de trinta anos, a partir desse trabalho, surge o Acompanhamento Terapêutico (ATs), com vários espaços de seu fazer e tentativa de formação de sua prática, assim, possibilitando a construção de um campo cada vez mais sólido para a atuação do Acompanhamento Terapêutico, remetendo a um caráter de proposta terapêutica, trabalho para novas áreas de atuação (PEIXEIRO, 2005).

Peixeiro (2009) traz a história da loucura para fazer uma reflexão, sobre o presenciado na área do envelhecimento, quando pensamos sobre deficiência torna-se um exercício da subjetividade de quem envelhece, o processo da loucura provocou mudanças de paradigmas culturais produzindo exclusão social e econômica do velho durante um período. Pensar a terceira idade ou pessoa idosa são recentes e reflete uma significativa mudança nas representações sociais do velho e da velhice. A cultura brasileira após os avanços ocorridos nas políticas da previdência social, designa a classe de velhos como sujeitos independentes, autônomos e com poder aquisitivo, diferenciando da imagem associada à velhice de inércia e pobreza ou doença.

Peixeiro (2009), aponta para a importância dessas transformações, onde propõe um envelhecimento isento, livre das perdas, das dores, beneficiando-se com as mudanças que vem ocorrendo tem grande importância e fazem parte de um processo de transição política, que vem ganhando visibilidade nos últimos anos na sociedade, tirando a pessoa idosa do lugar de caridade, para um lugar de direitos, como pode ser observado a partir da aprovação do Estatuto do Idoso no Congresso Nacional em 2003. 
Acompanhamento terapêutico no envelhecimento serve àqueles com dificuldades de circular no meio social, no caso, pessoas acometidas por estados depressivos, institucionalizadas ou em processo de desinstitucionalização, com demências, perdas significativas de vínculo, causadas por isolamento social. Acompanhamento terapêutico não é uma abordagem, mas sim, uma ferramenta. AT não é uma modalidade de ação restrita ou unicamente do psicólogo, mas, de toda a área da saúde, que pode se beneficiar com sua modalidade de intervenção. AT não é um acompanhante de idosos, mas uma modalidade clínica que se realiza no contexto social (BARBIERI, 2013).

\section{ACOMPANHAMENTO TERAPÊUTICO NA ÁREA DA VELHICE}

Barbieri (2013) faz a apontamento sobre as experiencias dos ATs com pessoas idosas, com frequência testemunham situações de violência velada na forma de sinceras boas intenções de familiares ou instituições. O AT tem um aumento de demanda, por sua experiencia no campo da saúde mental, torna-se fundamental, por oferecer e dar sustentação a esta prática, de função clínica, mas também política, conhecida por construir redes de apoio social que possibilita o indivíduo envelhecer com dignidade.

Acompanhamento Terapêutico é, uma ferramenta para construir um mundo próprio que seja compartilhável, reconhecível pelo outro. Ou seja, para voltar a ser escutado, continuar encontrando sentido para viver. Existe uma falta de habilidade para a velhice, tanto no âmbito macro como no micro-ssocial (GOLDFARB, 2004).

Apesar de ser construída no campo da saúde mental voltada para pacientes psicóticos, o Acompanhamento Terapêutico, tem sido utilizado como atendimento privilegiado na área do envelhecimento, tem muito a oferecer no campo da terceira idade, que ainda tem algumas carências (BARBIERI, 2008).

Barbieri (2008), questiona sobre o olhar dos profissionais e das instituições a respeito do processo do envelhecimento que ainda é notório, é tão carente por falta de mudanças e capacitações dos profissionais voltadas para o envelhecer, que agregue RC: 63489

Disponível em: https://www.nucleodoconhecimento.com.br/psicologia/acompanhamentoterapeutico 
habilidades adequada para o manejo técnico com a pessoa idosa, oferecendo um atendimento de inclusão para esse indivíduo da contemporaneidade, ou seja, 1 em cada 4 brasileiros será idoso até 2060 .

\section{PRECONCEITO NA TERCEIRA IDADE}

Parte inferior do formulárioA sociedade vive um mito do corpo jovem a qualquer preço, e o velho é pressionado pelas imagens de uma sociedade consumista, acaba se familiarizando, sem perceber os valores criado pela sociedade capitalista, onde se predomina o mito do corpo jovem, o velho é levado ao impossível, querer ser jovem também, ou seja, se percebe não servindo de parâmetro para nada, onde se exclui como sujeito sem um lugar de pertencimento (CHNAIDERMAN, 1996).

Chnaiderman, (1996), fala do tempo que maltrata o corpo já cansado com marcas psicológicas, fisiológicas, com fragilidade física, ao se depara com sua imagem corporal, não reconhece seu próprio corpo, passando por um processo de autodepreciação. Rejeição que causa uma grande dor psíquica, olhar esse corpo é não reconhecer mais porque passou por tantas mudanças, tantas cicatrizes, que não será cirurgia plástica ou milagres dos cremes que trará alívio, talvez se tivesse congelado uma parte da vida traria paz para essa dor. Na realidade não é o corpo, mas, a psique que está precisando de ser acolhida cuidada.

Chnaiderman (1996) faz uma reflexão sobre a atuação do profissional de saúde, que por não ter um olhar inclusivo acaba sem perceber, submete a pessoa idosa a um constrangimento, violação velada, por ignorar a existência materializada do sujeito em um corpo envelhecido. Nos consultórios acontecem com grande frequência, o profissional fazer perguntas aos familiares, acompanhante, ignorando o saber da pessoa idosa sobre si.

Ao sair do lugar tradicional de atendimento clínico, o AT oferece novas possibilidades no campo político e social para a pessoa idosa. Pode ser muito terapêutico o idoso ir ao teatro, cinema, parque entre outros passeios, dando outro significado à vida desse idoso, tirando-o do isolamento social e muitas vezes familiar, construindo ou

Disponível em: https://www.nucleodoconhecimento.com.br/psicologia/acompanhamento- 
recuperando hábitos que já haviam se perdido no tempo. AT é um dispositivo clínico sua característica está em ser um setting móvel, ou seja, não há lugar fixo para que ocorra o atendimento (REBELLO, 2006).

O propósito do acompanhamento terapêutico é renovar o território já trabalhado por ele, ressignificando o campo do envelhecimento para garantir um espaço de escuta e de construção de projetos voltados ao idoso. Apesar da existência do estatuto do idoso, ainda assim, o idoso sofre desamparo, sendo reprimidos e sufocados seus direitos, de ser humano social (GOLDFARB; LOPES, 2013).

O AT por ter seu fazer voltado para a inclusão, vem conquistando seu espaço, por ser uma clínica com visão política, seu objetivo é descortinar para dar visibilidade a um trabalho de mediações, tratando de sofrimentos com o olhar humanizado, deixa de forma bastante clara que não há divisão entre clínica e política. A Lei no 10216/2001, é um suporte para a clínica ampliada por garantir cidadania como efeitos políticos, possibilitando o contato com pessoas antes impedidas de circular pela cidade de forma livre (ARAÚJO, 2006).

Novaes (1995), fala sobre o processo de envelhecer é viver e suas experiencia subjetiva como indivíduo no contexto social, trazendo um conjunto de reflexões sobre existência vividas, é suas influências cultural sobre a figura da pessoa idosa.

\section{TODAS AS PERDAS SÃO GERADORAS DE SOFRIMENTO}

Luto não e propriamente só após a morte ou perda de alguém querido, mas também quando se perde algo, ou seja, envelhecer causa muitas perdas para o sujeito em si. Desde seu desenvolvimento como ser humano, a velhice é vista a última etapa, depois vem a morte sendo o processo da finitude (BAPTISTA, 2013).

Ao considerar que as pessoas envelhecem, aumenta a incidência de doenças crônicas, grande parte dos doentes crônicos será representado pela população idosa, - crescimento dessa classe e, consequentemente, das doenças crônicas degenerativas que passou a ser imprescindível o cuidado com o paciente idoso, ainda 
que não se almeje curá-lo, uma vez que as doenças mais prevalentes não são curáveis, pois, conforme a doença avança, o tratamento curativo não oferece um controle razoável (MACIEL, 2008).

Cabe salientar segundo o (OMS, 2008, p.9), que a pessoa idosa sofre um tratamento desvantajoso de saúde, o que é grave, ou seja, os idosos precisam de ambientes que auxiliem e apoiem com cuidados, voltados as alterações físicas e sociais decorrentes do envelhecimento. A filosofia dos cuidados paliativos vem ao encontro da necessidade e da realidade das pessoas idosas, pois considera o indivíduo como um todo, visa ao alívio da dor e do sofrimento, de ordem física, espiritual ou psicológica, além de incentivar a autonomia e prezar sua dignidade (BAPTISTA, 2013).

Acompanhamento Terapêutico caminha para a atualização dessa demanda, focando sua expansão para o campo do envelhecimento, investindo nesse indivíduo, seja a pedido da própria pessoa idosa ou de seus familiares, deseja para a pessoa idosa, injetar ânimo ao desejo quando este apresentar dificuldade em construir um projeto de vida diante do tempo que Ihe resta ou das limitações que possui, levando uma existência sem vivacidade (BAPTISTA, 2013).

Considerando o papel social que cada indivíduo desempenha, em cada fase de sua existência, é de extrema importância para a manutenção de sua autoestima. Porém, a aposentadoria, fase delicada ao lazer e ao descanso, que deveria servir de recompensa pelos anos de trabalho, pode vir a ser paradoxalmente, uma fase reforçadora da contradição de invalidez. Ou seja, o aposentado fica despojado do seu papel de trabalhador produtivo e esmagado pelo mercado, sua remuneração, em geral, nem o permite manter seu padrão anterior de vida. A perda de sua identidade social produtiva é retirada com a aposentadoria, esse e um luto muito significativo para a pessoa idosa (NEGREIRO, 1999).

Notadamente, se observa que o aspecto subjetivo do envelhecer é experienciar uma série de perdas. A pessoa idosa experiencia no processo de envelhecimento rupturas indesejáveis, de perda referentes, a perda do trabalho com a chegada da 
aposentadoria, morte do cônjuge ou amigos, familiares, perdas essas que pode levar a repressão de sua sexualidade e de sua capacidade de projetar e realizar (NOVAES, 1995),

A consequência de tantas perdas leva a pessoa idosa a quadros de depressão. Esse processo de mudanças ligadas a fase de envelhecimento e eventos traumáticos psicossociais podem ser considerados os principais responsáveis por desencadear episódios depressivos na idade avançada. Em casos mais graves, como o suicídio, torna-se imprescindível a participação da família para o desenrolar do tratamento (NEGREIRO, 2007).

Para a mesma autora a velhice e como um aprendizado adquirido, no qual o sujeito, exposto a sucessivos lutos e perdas, sente-se impotente mediante as situações, ou seja, esse condicionamento faz com que sentimentos de vazio e abandono tornem-se associados a experiencias de fracasso, reforçando na pessoa idosa a ideia de que nada pode reverter esse processo de luto.

Segundo a autora Rebello (2006), o envelhecimento é considerado um processo biopsicossocial, no qual fatores biológicos, sociais e psicológicos interagem entre si. Neste contexto entende-se que o envelhecer deixou de ser sinônimo de uma velhice única, categoria, fixa, determinada, para, aos poucos, adquirir um sentido heterogêneo da possibilidade de existência de múltiplas velhices.

Para a autora Rebello (2006), ainda é muito comum encontrar profissionais de diversas áreas que lidam com o processo de envelhecimento como uma categoria única principalmente na área médica que, muitas vezes, trata 0 ato de envelhecer unicamente sob o ponto de vista biológico, sem levar em consideração que o declínio do corpo físico é inevitável durante o processo do envelhecer, a pessoa idosa, com o passar do tempo, obviamente sofre algumas perdas irreversíveis do ponto de vista biológico, mas se nós aprisionarmos a esse olhar biologizante (visão ou aspectos biológicos), perderemos de vista as outras velhices, porém estas não necessariamente vinculadas ao declínio e as perdas. 
Goldfarb (1998), pontua com uma frase "O idoso precisa de muito mais que o mínimo necessário". Então, de que realmente precisa um indivíduo considerado na velhice? Frente aos aspectos parece-me que só os cuidados básicos de saúde, higiene e alimentação são insuficientes.

AT é uma ferramenta que possibilita o profissional de psicologia sair do seu contexto clínico tradicional para uma clínica inclusiva, para que não fique fragmentado, profissionais de outras áreas como Terapia Ocupacional, Enfermeiros, Fisioterapia, Educação Física, Assistente Sociais, Medicina, Fonoaudiologia, também fazem do AT sua ferramenta, pensando em uma clínica de laços e ética (ARAÚJO, 2006).

Para Generoso (2002) o AT tem uma visão de articulador, seu objetivo promover uma nova compreensão da atenção em Saúde Mental, pensando em menos danos, seu setting e de acolhimento humanizado inclusivo essa é orientação para seu fazer como profissional. Estará sempre voltado para o outro de forma social, atendendo as normas padrões, o psicólogo tem a ética do Conselho Federal de Psicologia (CFP) como uma bússola, sendo um suporte para o AT não deixar de ser ético seu trabalho em clínica ampliada

Buscou-se uma abordagem que desse um embasamento teórico para ser trabalhado com a clínica do Acompanhamento Terapêutico, sendo que a Gestaltterapia desempenha um papel social dentro dos movimentos de saúde, ela se coloca para estabelecer conexões intra/interinstitucionais por meio de algumas estratégias intra e extramuros, com apoio à inserção social, visita domiciliar, grupos terapêuticos fora do espaço tradicional (SILVA, 2007).

\section{GESTALT-TERAPIA COMO UMA CLÍNICA AMPLIADA}

Gestalt abdica dos saberes controlados entre paredes, para trabalhar na saúde primaria lançando-se em um espaço aberto de atuação, sem fronteiras demarcadas. Para lidar com o indivíduo no contexto onde os conflitos acontecem junto a sua realidade sociofamiliar, possibilitando o profissional na rotina cotidiana se depara face a face com as problemáticas, que envolve as demandas e ações para as quais RC: 63489

Disponível em: https://www.nucleodoconhecimento.com.br/psicologia/acompanhamento- 
vivencia e que não há um manual que direcione para lidar com as adversidades existentes (PALOMBINI, 2004).

Acompanhamento Terapêutico surgiu primeiramente no campo da saúde mental, e a Gestalt tem seu foco holístico voltado para movimentos de saúde. As duas clínicas têm um só objetivo; o ser humano e seu contexto social, juntas, são uma clínica psicossocial trabalhando as relações e advogando pelos direitos do sujeito, ampliando redes. Dessa forma, o saber de cada uma das clínicas está diretamente relacionado com a experiência singular, mas, que se unificam em um só objetivo, o ser humano (PALOMBINI, 2004).

\section{PROCEDIMENTOS METODOLÓGICOS}

Gil (2008) declara a principal finalidade da pesquisa exploratória, sendo, ampliar ideias sobre assuntos a ser investigado, para delinear o tema a ser pesquisado tendo em vista a formulação de hipóteses para ser pesquisado para o construto do trabalho, possibilitando descobrir novos enfoques dos posteriores.

A natureza das abordagens bibliográfica e qualitativa, tornam possível fazer levantamento de materiais já publicados, sua principal vantagem como pesquisa é permitir ao investigador a cobertura de uma gama de fenômenos muito mais ampla do que ficar apenas com entrevista da participante para a pesquisa. Neste artigo as palavras chaves utilizadas nas buscas de artigos científicos foram: acompanhamento terapêutico, envelhecer (GIL (2017)

A abordagem de conteúdo é um conjunto de técnica, a partir da análise documental com visão no público-alvo, sendo possível realizar roteiros de entrevista para levantamentos de dados juntamente com a entrevistada afim de obter compreensão sobre o Acompanhamento Terapêutico como dispositivo de uma psicóloga com o público idoso (BARDIN, 1994). 


\section{ENTRE A TEORIA E A PRÁTICA}

AT é um fazer clínico voltado para promover reinserção social potencializa em prol da pessoa idosa, procurando estabelecer vínculos de confiança, para favorecer a elaboração dos conflitos na totalidade vivida pelo indivíduo, participando do seu entorno afetivo, revelando os obstáculos para cura, muitas vezes psíquica, descobrindo potencialidades criativas, construindo enfim, possíveis projetos de felicidade junto ao sujeito que passa pela travessia do envelhecimento de forma acompanhada pelo psicólogo (GOLDFARB 2013).

Barbieri (2008), vai dizer que apesar de ser construída no campo da saúde mental voltada para pacientes psicóticos, o AT, tem contribui na área do envelhecimento, por promover a autonomia melhorando a organização subjetiva do idoso, trabalhando para ampliar apropriação de espaço público e privado pensando na saúde mental.

\section{Sendo corroborado pela vivência clínica do sujeito de pesquisa:}

AT é uma ferramenta que auxilia em vários contextos, trabalhando com diferentes problemáticas, se manifesta de forma a abordar as diferenças, saindo da clínica tradicional, para um lugar onde acontece a demanda seja na rua ou em casa. Trabalhar com a clínica AT, possibilita para articular com os diferentes saberes principalmente dentro da saúde, com profissionais enfermeiros(as), médicos(as), assistentes sociais, terapeutas ocupacionais e educadores, e os demais profissionais que trabalham no sistema do SUS e espaços escolares.

Barbieri (2008) confirma o fazer do AT e suas ações com outros saberes, por ser uma clínica que se diferencia dos modelos de atenção que pretendem o enquadramento do sujeito, em determinados padrões de atendimento terapêutico, ou seja, o acompanhante terapêutico cria possibilidades onde estiver o sujeito. Neste contexto

\section{o sujeito de pesquisa reafirma:}

O AT é uma clínica além do consultório tradicional, exige do psicólogo uma forma com possibilidades de dialogar e se colocar sem desqualificar os outros saberes, ter uma visão ampla interdisciplinar, para poder estar em espaços, de políticas públicas, conselho de saúde onde reverbera na saúde da população, são fazeres além do consultório tradicional, estar 
em diferentes espaços onde estiver o paciente idoso. O profissional AT estará sempre aberto ao diálogo visando sempre a autonomia do sujeito.

Barbieri (2008) pontua a importância do fazer do AT no campo da saúde, por entender que esse encontro de saberes de outras áreas pode fornecer um espaço de escuta $\mathrm{e}$ de construção de projetos para o futuro, ainda tão carentes na área do envelhecimento. Sendo testemunhado pela vivência do sujeito de pesquisa que:

O psicólogo AT como profissional, busca garantir um lugar que o idoso deseje celebrar a vida, se permitir fazer novos projetos se for sua vontade, ou até mesmo de ficar vivendo alguns processos de perda (luto) simbólico ou reais afetivos. O AT tem o dever de garantir cidadania ao sujeito idoso, advogando pela diferença, para esse sujeito estar no mundo e ser respeitado como tal, no meio familiar e social, visando sempre a inclusão do idoso e de seus direitos.

Para Peixeiro (2005), o AT, vem se consolidando na trajetória de seus trinta anos, conquistando vários espaços de formação de sua prática, possibilitando a construção de um campo cada vez mais sólido para a atuação do Acompanhamento Terapêutico, remetendo a um caráter de proposta terapêutica. Pensando nessa possibilidade o sujeito de pesquisa evidência que:

Não há um lugar determinado, para acontecer seu fazer, vai acontecer onde ele ter que acontecer, dentro do projeto terapêutico que pode ser remodelado a qualquer momento, AT é a clínica da rua, acontece no cinema, praça, café, praia, shopping onde tiver sujeito e demanda. Dentro de casa se for o que a demanda exigir no momento, seja por motivo de doença que impossibilite o paciente.

Barbieri (2013), levanta a importância de dar-se amparo e reconhecimento para a pessoa idosa, respeitar suas fragilidades, seu tempo como um ser, com um olhar humanizado. Trabalhando os laços de novas redes de relações de forma saudável, sem marginalizar, mas sim acolhê-los inserindo-os no contexto social e familiar como um ser digno pertencente a esse meio. Considerando relevante os apontamentos

\section{o sujeito de pesquisa, está confirmando que:}

O acompanhamento terapêutico deve ter disponibilidade para a escuta, ou seja, o sujeito idoso necessita de falar mais, o AT precisa saber o que é possível trabalhar com esse corpo que muitas vezes se encontra com 
limitações, fragilidades físicas que nessa passagem de idade são mais intensas por sintomas orgânico, falta de apoio, conflitos familiares, dores crônicas, situação de injustiça.

Barbieri (2013) fala da necessidade de ter uma prática como ATI (Acompanhamento Terapêutico de Idoso), em meados de 2005, foi formalizado junto ao CNPq um grupo de pesquisa, Cultura e Envelhecimento, em que se fez um estudo do Acompanhamento Terapêutico para Idosos, por entender da importância desse saber deixando claro que não havia uma modalidade específica de acompanhamento terapêutico para envelhecimento, mas um olhar voltado para o processo de envelhecimento.

Existem várias abordagens teóricas que conduzem a prática de AT, uma das mais disseminadas se apoia na psicanálise. $O$ acompanhamento terapêutico articula também com outras abordagens, pois seu objetivo é estar inserida no contexto social para garantir mais dignidade e menos sofrimento para a pessoa idosa, ou seja, e nessa perspectiva que se propõe a reflexão sobre atendimento terapêutico no envelhecimento, o resgate de um discurso e uma prática de laços de forma verdadeiramente amorosa que atende com delicadeza dessa etapa da vida do sujeito idoso (BARBIERI, BAPTISTA 2013). 0 sujeito de pesquisa salienta que todas as abordagens podem trabalhar com o dispositivo AT, e a primeira a corrobora com seu aprendizado:

A formação foi na abordagem psicanalítica, para complementar a especialização buscou-se bibliografias sobre o assunto independente da abordagem, assim, agregando mais conhecimento no contexto clínico por ter a vivência do AT, estar nos espaços onde as coisas acontecem de forma mais potencializado, na casa das pessoas na rua, lidando com várias vulnerabilidades dando muito mais potência e coragem, preparando o terapeuta para as demandas que surgem no consultório. Assim, a clínica do AT se faz importante por ser uma clínica ampliada, é inserindo todos que são rejeitados na vida, ou seja, o caso da pessoa idosa que vive o envelhecimento com sofrimento.

Para articular com a abordagem do Acompanhamento Terapêutico buscou-se GestaltTerapia por compartilharem dos mesmos saberes, desenvolver-se em espaços aberto atuação, característica particular da clínica AT, ou seja, sem fronteiras 
demarcadas, permitindo um encontro onde ambos são afetados, e nesse atravessar que acontece a interação social (PALOMBINI, 2004). o sujeito de pesquisa corrobora com sua vivência clínica com base na abordagem Gestalt-terapia por ser:

Uma clínica de inclusão que compartilha da mesma visão da clínica do AT, ou seja, o modo de trabalhar, alargando fronteiras sociais para incluir as diferenças, dar lugar ao outro para um encontro das diferenças. Na terceira idade ocorre a perda de personalidade, o medo de morrer, nesse momento a pessoa idosa precisa de alguém para ampliar e moldar as relações, sentimentos, comportamentos dependendo do fluxo. O AT vai contribuir para construção de uma nova identidade empoderando, resgatando o lugar social desse idoso, organizando de forma desejada pelos seus direitos. Porque nem sempre o adoecimento e doença, entender, que existe sim uma pessoa que sofre com sintomas. Porém, ter foco holístico voltado para os movimentos de saúde, assim, as duas clínicas caminham juntas com o mesmo objetivo, o ser humano e seu contexto social, dessa forma unificassem em uma clínica com visão ampliada trabalhando as relações advogando pelos direitos do sujeito.

Ao fazer uma reflexão sobre as intervenções do AT observa-se que seu decorrer vem de estratégias relacionadas a transferência, sua forma é de vínculo de confiança que coordena os procedimentos de longo prazo, sendo uma tática relacionada ao momento da intervenção. As táticas de intervenções vão depender de cada caso, não existe uma atividade padrão. Mais, é pensado na problemática de cada sujeito. $\mathrm{O}$ objetivo do AT é de provocar no outro a renovação de um projeto de vida, por meio de um vínculo sem dependência, que envolve suporte, apoio e continência permitindo a pessoa idosa elaborar seus lutos para direcionar seus interesses para novos objetivos, sempre em conformidade com seu desejo (GOTTER, 2006).

\section{CONSIDERAÇÕES FINAIS}

Ao fazer uma previa reflexão percebe-se a postura do fazer da abordagem do AT, sua relação clínica vai além da subjetividade do indivíduo a partir da sua escuta diferenciada trabalhando como mediador, construindo caminhos para além do consultório de forma coerente é ética. Um percurso que exige do AT, ter habilidade e disponibilidade para estar no território onde as questões do envelhecimento acontecem, envolvendo as mudanças corporais e psicológica do indivíduo. 
Pensando em fazer diferença como psicóloga no contexto social, agreguei no meu currículo os conhecimentos do Acompanhamento Terapêutico, foi um aprendizado que veio para agregar o fazer profissional de forma ampla sem deixar de ser ética. Possibilitando construir caminhos de autonomia reinserção social juntamente com o indivíduo.

Destaca-se que a hipótese foi confirmada, enfatizando que, a teoria e a prática se consolidam, sendo feito um paralelo com a clínica do acompanhamento terapêutico. De forma ampla verificou-se a participação do fazer do Acompanhamento Terapêutico como clínica ampliada, sua atuação é muito nova caminha a passos lentos para esse grupo que cresce a cada dia na sociedade. Muito se é falado sobre pessoa idosas em pesquisas científicas, mas pouco é concretizada no meio social. É preciso pensar, que ainda há negligência por parte de profissionais da saúde e de seus próprios familiares.

Como demanda a partir dos relatos, observa-se que esse grupo apresenta uma experiência, que impossibilita o sujeito de todas as formas, física e psicológica por se sentir desamparado provocando crises de subjetividade. $O$ acompanhamento terapêutico possibilita a inclusão articulando as diferenças com uma leitura ampliada da problemática para atravessar de forma fluida e humanizada.

Mediante a tais colocações, é preciso atentar para as limitações do presente trabalho, pois apesar de ser uma abordagem bibliográfica consultada para compreender o fazer do acompanhamento terapêutico, percebe-se que muito se fala sobre o idoso, porém tem poucos estudos científicos sobre esta população, com a ação do acompanhamento terapêutico como ferramenta do psicólogo. No processo de construção do trabalho foi possível encontrar poucos artigos sobre acompanhamento terapêutico específico com pessoas idosas. Mais pesquisas precisam acontecer no intuito de preparar os profissionais para cuidar das pessoas idosas.

\section{REFERÊNCIAS}

ARAÚJO, Fábio. Um Passeio Esquizo pelo Acompanhamento Terapêutico: dos especialismos à política da amizade. Niterói: Editoração eletrônica, 2006. 
BERGER, E, MORETTIN, A. V \& NETO, L. B.- História. In Equipe de Acompanhantes Terapêuticos dos Hospitais-Dia a Casa (org.). A rua como espaço clínico. São Paulo. 1991.

BARBIERI, N, A. - Travessia do tempo: Acompanhante terapêutico e envelhecimento. São Paulo 2013. ed. Casa do Psicólogo.

BARBIERI, N, A. - Escuta e criação de projetos: Observações sobre a clínica do acompanhamento terapêutico e o envelhecimento. In. (Org.) 2008. BARBIERI, N, A. - Travessias do tempo: Acompanhante terapêutico e envelhecimento. São Paulo 2013. ed. Casa do Psicólogo.

BARDIN, I. Análise de conteúdo. Lisboa: Edições Setenta,1994.

BARBIERI, N, A. - (BAPTISTA, 2013). Travessias do tempo: Acompanhante terapêutico e envelhecimento. São Paulo 2013. ed. Casa do Psicólogo.

BARBIERI, N, A. BAPTISTA, C, G. - Travessias do tempo: Acompanhante terapêutico e envelhecimento. São Paulo 2013. ed. Casa do Psicólogo.

BAPTISTA, C, G. - A acompanhando a morte - reflexão sobre o acompanhamento terapêuticos no envelhecimento sob a perspectiva da morte. - (Org)- BARBIERI, N, A. - Travessia do tempo: Acompanhante terapêutico e envelhecimento. São Paulo 2013. ed. Casa do Psicólogo.

BARBIERI, N, A. - Travessias do tempo: Acompanhamento terapêutico e envelhecimento. São Paulo 2013. ed. Casa do Psicólogo.

CHNAIDERMAN, M.- Omito do corpo jovem a qualquer preço. In. (Org.) -1996.

FOUCAULT, M. - (1975 a 1976) - Em defesa da sociedade - Curso com Collége de France. In. Fontes. M. - São Paulo. 2005. 
GONÇALVES, A. M, SENA, R. R. A reforma psiquiátrica no Brasil: contextualização e reflexos sobre o cuidado com o doente mental na família. Rev Latino-am Enfermagem. Minas Gerais - 2001 Disponível em:< http://www.revistas.usp.br/rlae/article/viewFile/1551/1596>. Acesso em: fev.2019.

GENEROSO, Cláudia Maria, FONSECA, Aurélio \& MAIA, Maria Silvana. O Projeto de Trabalho da Clínica Urgentemente: Novos dispositivos aplicados na ampliação da clínica em saúde mental e suas interlocuções com o campo social. Revista da Clínica Urgentemente: A Rede - Clínica ampliada em Saúde Mental: Acompanhamento Terapêutico. Belo Horizonte, ano I- $n^{\circ} 1$, setembro 2002.

GOLDFARB, D, C. LOPES, R, G, C.- Interfaces necessária entre a psicogerontologia e o acompanhamento terapêutico. - In. (Org.) - Travessias do tempo: Acompanhamento terapêutico e envelhecimento. São Paulo 2013. ed. Casa do Psicólogo.

GOLDFARB, D. C. (2004). Corpo e temporalidade: aporte para uma clínica do envelhecimento. In Revista Kairós, 1(1), 103-110. São Paulo: Educ. In. (Org) Travessias do tempo: Acompanhamento terapêutico e envelhecimento. São Paulo 2013. ed. Casa do Psicólogo.

GOLDFARB, D. C. (2004). Do tempo da memória ao esquecimento da história: um estudo psicanalítico das demências. Tese de doutorado, Instituto de Psicologia, Universidade de São Paulo, SP, Brasil - - In. (Org.) - Travessias do tempo: Acompanhamento terapêutico e envelhecimento. São Paulo 2013. ed. Casa do Psicólogo.

GOTTER, ELVIRA - (2006) O grito mudo do desamparo: um episódio na metrópole. In (Org) - Travessias do tempo: Acompanhamento terapêutico e envelhecimento. São Paulo 2013. ed. Casa do Psicólogo.

GIL, Antônio Carlos. Como elaborar projetos de pesquisa. 5aㅡ. ed. São Paulo: Atlas, 2017. 
GIL, Antônio Carlos. Métodos e Técnicas de Pesquisa Social. 6ª ed. - São Paulo. Atlas. 2008.

MACIEL, M. G. (2008). Definições e princípios. In R. A. Oliveira (Ed.). Cuidado paliativo (p. 15-33). São Paulo: Conselho Regional de Medicina do Estado de São Paulo. - (Org) - BARBIERI, N, A. BAPTISTA, C, G. - Travessias do tempo: Acompanhamento terapêutico e envelhecimento. São Paulo 2013. ed. Casa do Psicólogo.

NOVAES M, H. Psicologia da terceira idade. Petrópolis: Vozes, 1995.

NEGREIROS, T, C, de G, M. - A nova Velhice: Uma visão multidisciplinar. 2ª . ed. Revinter. Rio de Janeiro - 2007.

NEGREIROS TC. Gênero e geração: reflexões sobre o contemporâneo processo de envelhecer. In Psicologia clínica: pós-graduaçõ \& pesquisa. Vol. 11. Rio de Janeiro: Departamento de Psicologia PUC-RJ, 1999, pp 107-16. (Org) In NEGREIROS, T, C, de G, M. - A nova Velhice: Uma visão multidisciplinar. 2ª . ed. Revinter. Rio de Janeiro - 2007.

NERI, A.L. Envelhecer num país de jovens. Significados de velho e velhice segundo brasileiros não idosos. Campinas: Editora da UNICAMP, 1991. In (Org) JUNIOR, G, P. - Sobre alguns conceitos e características de velhice e terceira idade: uma abordagem sociológica.

ORGANIZAÇÃO MUNDIAL de SAÚDE. (2008). Cidade amiga do idoso. Organização Mundial de Saúde. (Org) - BARBIERI, N, A. - Travessia do tempo: Acompanhamento terapêutico e envelhecimento. São Paulo 2013. ed. Casa do Psicólogo.

PALOMBINI, A. (2004). Acompanhamento terapêutico na rede pública: a clínica em movimento. Porto Alegre: ed. da UFRGS. In. (Org). FRAZÃO, L, M. Fukumitsu, K, O. - A clínica, apelação psicoterapêutica e o manejo em Gestalt-terapia. Sammus. São Paulo 2015. 
PEIXEIRO, M, H. - Sobre o acompanhamento Terapêutico e sua abertura para o campo do envelhecimento: Da loucura à velhice. 2005. In. (org.). - BARBIERI, N, A. - Travessias do tempo Acompanhamento terapêutico e envelhecimento. São Paulo 2013. ed. Casa do Psicólogo.

PEIXEIRO, M, H. (2009). Paralisia do tempo e vazio no envelhecimento. In. (Org.) - BARBIERI, N, A. - Travessias do tempo Acompanhamento terapêutico e envelhecimento. São Paulo 2013. ed. Casa do Psicólogo.

REBELLO, L. - Acompanhamento Terapêutico com Idosos: Além do Mínimo Necessário (2006). In. (org.). BARBIERI, N, A. - Travessias do tempo: Acompanhamento terapêutico e envelhecimento. São Paulo 2013. ed. Casa do Psicólogo.

SILVA, M. V. O, Entrevista. In: A clínica social das psicos. In-tensa. Ex-tensa. Universidade Federal da Bahia; Programa de intensificação de cuidados a pacientes psicóticos. Salvador, ano I, 2007, p. 15-36. In. (Org) - FRAZÃO, L, M. Fukumitsu, K, O.-A clínica, a relação psicoterapêutica e o manejo em Gestalt-terapia. Summus. São Paulo, 2015.

TEBET, R. (senador)- Senado Federal-Estatuto do Idoso Dispositivos Constitucionais Pertinentes Lei $n^{\circ} 10.741$, de $1^{\circ}$ de outubro de 2003, Norma Correlatas Índice Temáticos. Brasília-2003.

Enviado: Setembro, 2020.

Aprovado: Outubro, 2020. 